\title{
A New Model of Tourism Enterprise Management under the Concept of Eco-tourism Management
}

\author{
Wenjing LV \\ Born in July 1982, Female,Han, People from Shandong, Pingyin, Undergraduate, lecturer, The \\ research direction is the management of tourism enterprises and the management of tourism \\ resources \\ Qilu Normal University \\ Shandong,China250013
}

\section{Keywords: Eco-tourism; Enterprise management; Eustainable development}

\begin{abstract}
With the needs of the tourism market and the improvement of the quality of the ecological tourism in the domestic status, strengthen the management in the process of eco-tourism development is the foundation to realize the sustainable development of ecological tourism service industry. The core of eco-tourism management is to deal with the relationship between economic system and ecological system. This paper discusses and analyzes the new mode of the management of eco-tourism enterprises.

As a national and even the world's tourism industry development direction and new ideas of ecotourism is the continuation and performance of sustainable development. And the United Nations sets up eco-tourism year is a manifestation of the importance of eco-tourism and the emergence of a new upsurge in tourism. At present, many definitions of eco-tourism also have their own characteristics, like attaches great importance to the ecological tourism in Japan, the Tourism Association has given the following definition: firstly, it is a kind of tourism on the natural resources, cultural and historical resources in the ecological tourism activities; secondly, it should not undermine the existing but to protect these resources and in the process of management; thirdly, it is to protect the resources based on the continuation of development of tourism (including sightseeing, protection and development), provided to the natural charm and sustainable tourism consumers of tourism services in achieving the three basis points.

From the above definition, it can be seen that in the natural ecological tourism, because of its influence, development scale and unique properties which make it impossible for the tourism industry and pillar mainstream but as an emerging characteristics of service products. Although it is not possible to measure the value of eco-tourism as a measure of the value of eco-tourism, it has a valuable experience in achieving sustainable development and demonstrating the role of other people in tourism. Eco-tourism in China's tourism industry at present only slightly emerged in the initial stage, the pilot and exploration, but with the needs of the tourism market, the reform of the management system to improve the quality of the whole tourism industry in China, and it will also gradually improve and enhance its position in the industry. In the process of eco-tourism development, it is the foundation and key to realize the sustainable development of eco-tourism service. Due to the complexity and lack of practice of ecological tourism management so that it still has some problems, as the tourism core and key stakeholders of tourism enterprise management according to the management theory of ecological tourism in perfect and updating.
\end{abstract}

\section{The Necessity of Ecological Management of Tourism Enterprises}

Generally speaking, the organization of tourism enterprises are different in different countries, but generally divided into local tourism companies and domestic and foreign travel agents, while it also from the aspect of play, accommodation and transportation shopping. In our country, tourism enterprises can be divided into three kinds: local collective tourism enterprises, individual retail investors and foreign investment enterprises. They are in direct contact with tourists, tourism resources and government agencies, so the impact of their business activities also affect the ecological environment, consumer satisfaction and the promotion of cultural and social norms. But on the other hand, they are not directly responsible for the ecological environment and the humanities and social and cultural cost responsibility, so the need to standardize its business 
practices from the outside to improve their sense of social responsibility and environmental awareness and to improve the ability of environmental protection from behavior. In addition from the tourism enterprise itself, based on the appropriate use of resources and reasonable protection, it must also have the consciousness of ecological environment in obtaining economic benefits on the basis of the service based on the tourists which should also educate tourists that play the initiative in accepting the foundation of government management.

Firstly, only in a ecological economic system of self configuring, reduction, organization, regulation, tourism enterprises can have orderly development, so the enterprise must be based on eco-tourism concept which should fully realize the importance of ecological management, fully understanding and correctly handle the relationship between resource flow and economic flow and ecological environment. With good ecological and economic system in the process of development of tourism resources, it is the only way to effective exploitation of resources to survival of the fittest.

Secondly, as the ecological tourism industry main tourism enterprises, through the complex network of relationship between the natural ecological environment and tourist other subjects interact, the essence of the ecological relationship management of tourism enterprises is to correctly handle the various members of the ecological network, and its ecological attributes also makes it the realization of ecological tourism of the key to the development of a ring.

Moreover, in addition to the government's role in promoting and enhancing their awareness of environmental protection, tourism enterprises' strengthen ecological management is another source of social and economic benefits. In terms of social benefits, it is mainly through the introduction of ecological products and ecological services to win the support of tourism consumers, so as to enhance the enterprise's eco-green image. And in the economic interests of this important aspect, it can be through government incentives, improve management, institutional innovation, technical level and other means to save energy to reduce costs.

\section{The New Management Model of Eco-Tourism}

New external management model. For the highly miniaturized and ecological tourism enterprises (including discrete external, industry associations and government etc.), new management mode can be carried out through several ways: Firstly, it is the association in charge of ecological tourism industry which can set up a certification system for some essential ecological management methods, to be certified to meet the requirements of the enterprise, and in some aspects traffic policy concessions to improve the consciousness and enthusiasm of ecological management of tourism enterprises through this method. Secondly, it is strictly controlled in terms of business license issued, and only to achieve the corresponding ecological protection awareness, eco-tourism management experienced enterprises can apply for this certificate. And before or after licensing in violation of the principles of environmental protection of enterprises that can adopt or revoke its business license which shall not be issued a direct way to carry out standardized management. Thirdly, the external management of eco-tourism enterprises can also be carried out by the association for the development of eco-tourism industry norms that can include empirical norms, practices, norms, standards and so on.

New business management model. Firstly, with the development of eco-tourism, the management concept of tourism enterprises has changed. The traditional management mode and lack of innovation and development, and even obstacles restricting the development of enterprises means the transformation of management idea enhancing innovation management consciousness, cultivating ecological consciousness of management which has become an important content of the new model of ecological management in tourism enterprises. The so-called ecological management concept is in the actual basis of tourism enterprises on cleaner production, green marketing and ecological finance, strategy, culture, management philosophy after considering the formation of ecological tourism management model are really suitable for the development of tourism enterprises. Such as the establishment of tourism Swallow Edinburgh Greens Hotel's management concept can not only greatly reduce energy consumption, but also to follow the fundamental path of sustainable development and management. Another example of eco- tourist scenic spots development enterprises should innovate management mode in the ecological balance weight in the economic 
management theory that emphasis on the development of local products, management, functional zoning results as traceability management mode. In addition, the concept of travel agency management should be based on sustainable development and green marketing, the pursuit of corporate interests and not to relax the interests of the social environment are the principle of green marketing. As to the natural resources as a product of the travel agency enterprises with the ecological environment of the friendly property have become important aspects of its management philosophy.

Secondly, talents as the main tourism resources needs more attention, and make full use of innovative talents to promote the development of enterprises. Therefore, in the tourism enterprise management model, it should be trained in line with the ecological environment of the development of the talent team to improve the professional quality of personnel and management level, and the level of innovation as an important part. The training plan should be combined with the actual situation of the enterprise and the background of tourism ecological management improving the incentive promotion system through scientific training to improve the ecological tourism enterprises and innovative talent management model.

Thirdly, the scientific and reasonable management system and management organization of tourism enterprises. Management mechanism is the foundation of enterprise management, the management mechanism of domestic enterprises in the presence has a lot of problems, such as ecological tourism pays more attention to the protection of the ecological environment, the profit is not enough to pay all the expenses, resulting in tourism enterprises are facing the problem of shortage of funds. And with problems of ecological tourism management in the legal system which is not perfect and lead to ecological tourism industry management system is not smooth. Management problems and tourism enterprises due to lack of supervision. For all these problems, it needs to solve the problem that is to improve the management mechanism. The first is to improve the management system, and the tourism enterprise management system should be established on the basis of the related laws and regulations, and follow the ecological protection and rational utilization of resources and the principle of establishing the framework of pollution control. The actual operation and practice in line with the ecological management should be based on the formation and implementation of this management system.It is necessary to improve the ecological management organization, which is the essential element of the implementation of the system. The establishment of internal ecological organization structure and external network ecological chain, and change the traditional Pyramid and flat organizational structure management mode (reduced management) are fully reflected in the tourism enterprises to improve organizational structure concept of ecological management process that has been fully integrated. In addition, it can also be added to the supervision department of the ecological management department to supervise the enterprise ecological management seriously and effectively in the end.

Fourthly, The network and digital model of enterprise ecological tourism management. With the advent of network and digital era, in the process of enterprise management, it will be introduced into and technology. Through a combination of digital and network technology in the eco-tourism management, establishing the network module management mode and digital resources ecosystem, not only saves management costs, but also ensure the rational use of resources reducing the waste of resources, and from the management of enterprises to improve efficiency, giving full play to the ecological tourism enterprises and other enterprises competitive advantages.

Fifthly, The good quality of service is an important aspect of innovation management mode of ecological tourism enterprises. Because it not only affects the visitors to the scenic tourism enterprises, it will affect the sustainable development of ecological tourism industry. With the development of eco-tourism industry, tourists' consumption level of tourism products and services is improved, and the requirements for product quality and service quality are improved. How to meet the needs of consumers, how to improve the quality of service are major tests of the tourism enterprises in their own ecological management process. At present, the enterprise is mainly reflected in the attention to the details to improve the quality, such as the number and size of control to improve the tourists travel safety and tourist satisfaction. For example, ecological civilization tourism interpretation system, providing personalized and standardized services in the arrangement 
of the travel route and catering, according to the different needs of tourists to provide different service mode. In short, in the tourism enterprise innovation management mode, intimate service, meticulous service, quality service, improve the quality of eco-tourism services, and then create eco-tourism enterprise quality projects.

In addition, the ecological tourism enterprises also needs innovation in other aspects of management mode, such as respect for the local culture and customs, education and communication to consumers and tourists improving their humanistic and social cultural sensitivity or in the management process of the main development of local specialty products, the main build local culture, the local people and resources, reducing the waste of resources and increasing revenue, as with the approach of cooperation which will be local agencies involved.

\section{Conclusion}

At present, as consumers ecological consciousness, Internet resources and from extensive to intensive use of the conversion, legislation and tourists and the community to actively participate in relevant technological and institutional progress, China's ecological tourism management enters a new stage. Ecological tourism management as a major ideological change at this stage, in which core through innovative management mode, it can inherit the management philosophy of sustainable development coordination and handle the relationship between economic system and ecological system. Only the implementation of ecological management of tourism enterprises will have a strong competitive power and sustainable development.

\section{References}

[1] Xueyan Hou.Management strategy of tourism enterprises based on ecological attributes[J].Enterprise research, 2012,1(2):31-32.

[2] Rui Song.Eco-tourism: multi objective and multi agent symbiosis[D].Chinese Academy of Social Sciences, 2003. 